\title{
PENGARUH PERBEDAAN INTENSITAS CAHAYA TERHADAP PERTUMBUHAN DAN PERKEMBANGAN LARVA KERANG MUTIARA (Pinctada maxima, Jameson, 1901) SKALA LABORATORIUM
}

\author{
Fitra Wira Hadinata, Sahala Hutabarat, Djoko Suprapto*)
}

Jurusan Perikanan, Fakultas Perikanan dan Ilmu Kelautan, Universitas Diponegoro

Jl. Prof. H. Soedharto, SH, Tembalang Semarang. 50275 Telp/Fax (024) 7474698

\begin{abstract}
Abstrak
Pengembangan budidaya laut sejauh ini belum seintensif pengembangan budidaya air tawar dan air payau. Terbatasnya penyebaran informasi teknologi budidaya beberapa komunitas budidaya laut, antara lain kerang mutiara, menjadi salah satu kendala dalam upaya perluasan usaha bagi pembudidaya kerang mutiara tersebut. Intensitas cahaya berpengaruh terhadap pertumbuhan dan perkembangan larva kerang mutiara. Intensitas cahaya yang tidak terlalu tinggi dapat melindungi tubuh larva dari radiasi ultra violet. Larva kerang mutiara bersifat fototaksis positif dan umumnya selama metamorfose larva membutuhkan intensitas cahaya yang sesuai. Pemberian dosis pakan alami berupa alga diawal pemeliharaan sebesar 7000 individu/ml/hari dan terus ditambah 1000-1500 individu/ml/hari selama 17 hari masa pemeliharaan. Pada media pemeliharaan larva diperoleh suhu air berkisar 28-29 ${ }^{\circ} \mathrm{C}$, salinitas 32 ppt, dan pH air 8. Berdasarkan pengamatan secara deskriptif, intensitas cahaya berbeda mempengaruhi pertumbuhan larva kerang mutiara (P. maxima). Intensitas cahaya 50 dan 100 lux cenderung mempengaruhi pertumbuhan dan laju sintasan larva kerang mutiara.
\end{abstract}

Kata Kunci : Pinctada maxima, Intensitas Cahaya, Pertumbuhan, dan Perkembangan

\begin{abstract}
The development of mariculture in general so far has not been as intensive as the development of freshwater aquaculture and the brackish water. The limited development of information technology of mariculture, such as pearl shells, becomes one of the constraints in the efforts to expand the business for the pearl. Light intensity has the effects to the growth and maturation of the pearl shells larvae. The low intensity of light can protect the larvae against by ultra violet radiation. Oyster larvae are fototaksis positive and generally require appropriate light intensity during the larvae metamorphosis. The feeding of algae at the beginning of the maintenance is 7000 individuals / $\mathrm{ml} /$ day and was continuously added into 1000-1500 individual / $\mathrm{ml} /$ day during 17 days the observation. In the larval rearing media was known that the water temperature about $28-29{ }^{\circ} \mathrm{C}, 32$ ppt salinity, and 8 water $p H$. Based on descriptive observation, different light intensities affect larval growth of pearl shells $(P$. maxima). Light intensity of 50 and 100 lux were likely to affect the growth and survival rate of pearl shells larvae.
\end{abstract}

Keywords: Pinctada maxima, Light intensity, Growth and Maturation

\section{Pendahuluan}

Indonesia sebagai salah satu produsen mutiara dunia patut dibanggakan, terutama karena mutiara yang diproduksi merupakan jenis south sea pearl. Mutiara jenis ini hanya dihasilkan dari kerang jenis Pinctada maxima dan merupakan jenis mutiara termahal di dunia (Sujoko, 2010).

Jenis kerang penghasil mutiara antara lain Pinctada margaritifera, P. maxima, P. fucata, Pteria sternia, dan Pteria penguin. Adapun yang dikembangkan di Indonesia adalah P. maxima, P. margaritifera, dan P. penguin (Sutaman, 1993; Winanto, 2004).

\footnotetext{
${ }^{*}$ Penulis Penanggung Jawab
} 
Berkembangnya budidaya mutiara ternyata menjadi pemicu meningkatnya permintaan spat dan kerang mutiara siap operasi. Namun spat yang berasal dari alam jumlahnya terbatas, sangat fluktuatif dan dipengaruhi musim (Winanto, 1996). Produksi melalui hacthery merupakan pendekatan yang paling memungkinkan dalam penyediaan spat (Rupp et al., 2005).

Pada mulanya, teknologi pembenihan kerang mutiara terkesan "rahasia" karena hanya dikuasai oleh teknisiteknisi asing yang kebanyakan dari Jepang bekerja di hatchery (tempat pembenihan). Kerang mutiara juga masih terbatas pada perusahaan besar yang kebanyakan PMA (Penanam Modal Asing). Menjelang tahun 2000, berkembanglah hatchery yang dimiliki oleh pengusaha lokal dan dikerjakan oleh tenaga domestik akan tetapi berbagai teknologi pembenihan hatchery masih belum dikuasai perusahaan lokal (Sujoko, 2010).

Pengembangan perikanan budidaya dalam rangka pembangunan kelautan dan perikanan dilakukan untuk mewujudkan visi Menteri Kelautan dan Perikanan yaitu menjadikan Indonesia sebagai produsen kelautan dan perikanan terbesar di dunia pada tahun 2015. Oleh karena itu, kebijakan pembangunan perikananan budidaya diimplementasikan dalam bentuk program peningkatan produksi perikanan budidaya (Sujoko, 2010).

\section{Materi dan Metode Penelitian}

\section{A. Materi Penelitian}

Materi yang digunakan dalam penelitian adalah larva kerang mutiara (P. maxima, Jameson, 1901) di PT. Autore Pearl Culture, di Desa Malaka, Kecamatan Pemenang, Kabupaten Lombok Utara.

\section{B. Metode Penelitian, Pengolahan dan Analisis Data}

Metode yang digunakan dalam penelitian ini adalah metode eksperimental dengan menerapkan teknik pemeliharaan larva kerang mutiara $(P$. maxima) dengan pemberian perbedaan intensitas cahaya pada masing-masing perlakuan skala laboratorium. Data diperoleh dengan cara pengamatan dan pencatatan secara langsung dan sistematis terhadap sintasan dan pertumbuhan larva kerang mutiara ( $P$. maxima) mulai dari stadia D-larva sampai dengan stadia plantigrade.

Penelitian pendahuluan ini dilakukan di laboratorium Ilmu-ilmu Perairan, Kampus Perikanan Tembalang, Semarang, pada tanggal 20 Maret 2012 jadi untuk menentukan intensitas cahaya yang digunakan dalam penelitian utama. Kegiatan ini bertujuan untuk mengetahui jarak dari lampu ke permukaan media pemeliharaan untuk mendapatkan intensitas cahaya yang dikehendaki bagi setiap perlakuan.

Penelitian pendahuluan dilakukan dengan menggunakan stoples $11 \mathrm{~L}$ yang diisi air laut sebanyak $10 \mathrm{~L}$. Lampu Philips 11 Watt digunakan sebagai sumber cahaya dan lux meter sebagai alat pengukur intensitas cahaya. Lampu dan lux meter diletakkan di permukaan air, kemudian lampu diatur jaraknya dari permukaan air sehingga didapatkan intensitas cahaya 0, 50, 100, 150, dan 200 lux.

Dari hasil penelitian pendahuluan kemudian ditentukan jarak antara lampu ke permukaan air agar mendapatkan intensitas cahaya 0, 50, 100, 150, dan 200 lux. Lampu yang digunakan dalam penelitian ini adalah lampu Philips 11 watt. Masing-masing ulangan 0 lux (tidak menggunakan lampu, ditutup rapat dengan menggunakan plastik hitam), 50 lux dengan jarak $68 \mathrm{~cm}, 100$ lux dengan jarak $49 \mathrm{~cm}, 150$ lux dengan jarak $37 \mathrm{~cm}$, dan 200 lux dengan jarak $28 \mathrm{~cm}$ dari permukaan air media pemeliharaan ke lampu penerangan.

Pengukuran salinitas, suhu air, dan pH dilakukan dua hari sekali pada media air yang digunakan sebagai media pemeliharaan dari larva kerang mutiara $P$. maxima pada tiap perlakuan. Pengukuran salinitas menggunakan alat refraktometer, suhu air dengan menggunakan termometer, dan pengukuran $\mathrm{pH}$ menggunakan $\mathrm{pH}$ paper.

\section{Hasil dan Pembahasan}

Dari penelitian yang telah dilakukan didapat hasil meliputi: gambaran umum lokasi penelitian, pemberian pakan alami, parameter media pemeliharaan, data pertumbuhan, dan laju sintasan larva kerang mutiara yang diberikan intensitas cahaya berbeda.

\section{Pemberian Pakan}

Pemberian pakan alami larva berupa algae dikultur secara masal pada laboratorium pakan alami, jenis algae yang dikultur antara lain Isochrysis tahiti, I. galbana, Pavlova sp., Chaetoceros amami, C. simplex, C. mulleri, dan C. gracilis. Dosis pemberian pakan larva kerang mutiara mengalami penambahan jenis dan volume setiap hari. Data dosis pemberian pakan alami dapat dilihat pada Gambar 1.

Jenis pakan yang dikultur pada laboratorium pakan alami yang diberikan sebagai pakan pada larva kerang mutiara antara lain Isochrisys tahiti, I. galbana, Pavlova sp., Chaetoceros amami, C. simplex, C. mulleri, dan C. gracilis. Pada laboratorium pakan alami, alga dikultur secara masal. Proses kultur terdiri dari beberapa langkah yaitu proses sterilisasi alat dan media air yang digunakan serta pengujian sampel alga dari kontaminan.

Pemberian dosis pakan larva kerang mutiara, diberikan berdasarkan pengamatan secara visual terhadap kondisi lambung larva. Pengecekan lambung larva kerang mutiara dilakukan setiap hari. Selain itu disesuaikan dengan stok alga yang ada di laboratorium pakan alami. Pemberian pakan dibagi menjadi dua periode yaitu pagi dan sore hari.

Fase awal yaitu fase embrio saat masih berupa telur, pada saat fase ini embrio tidak diberi makan; fase D-larvaumbo awal yaitu pada saat umur 2-6 hari dosis makanan diberikan sebanyak 7000 - 11000 individu/ml/hari; fase umbo akhir-eye spot dengan dosis 12500 - 19500 individu/ml/hari, dan fase ini berjalan dari umur 7 - 14 hari; fase pediveliger-plantigrade (15-18 hari) dosis pakan pada fase ini didapatkan sebesar 20500 - $22500 \mathrm{individu} / \mathrm{ml} / \mathrm{hari}$ 


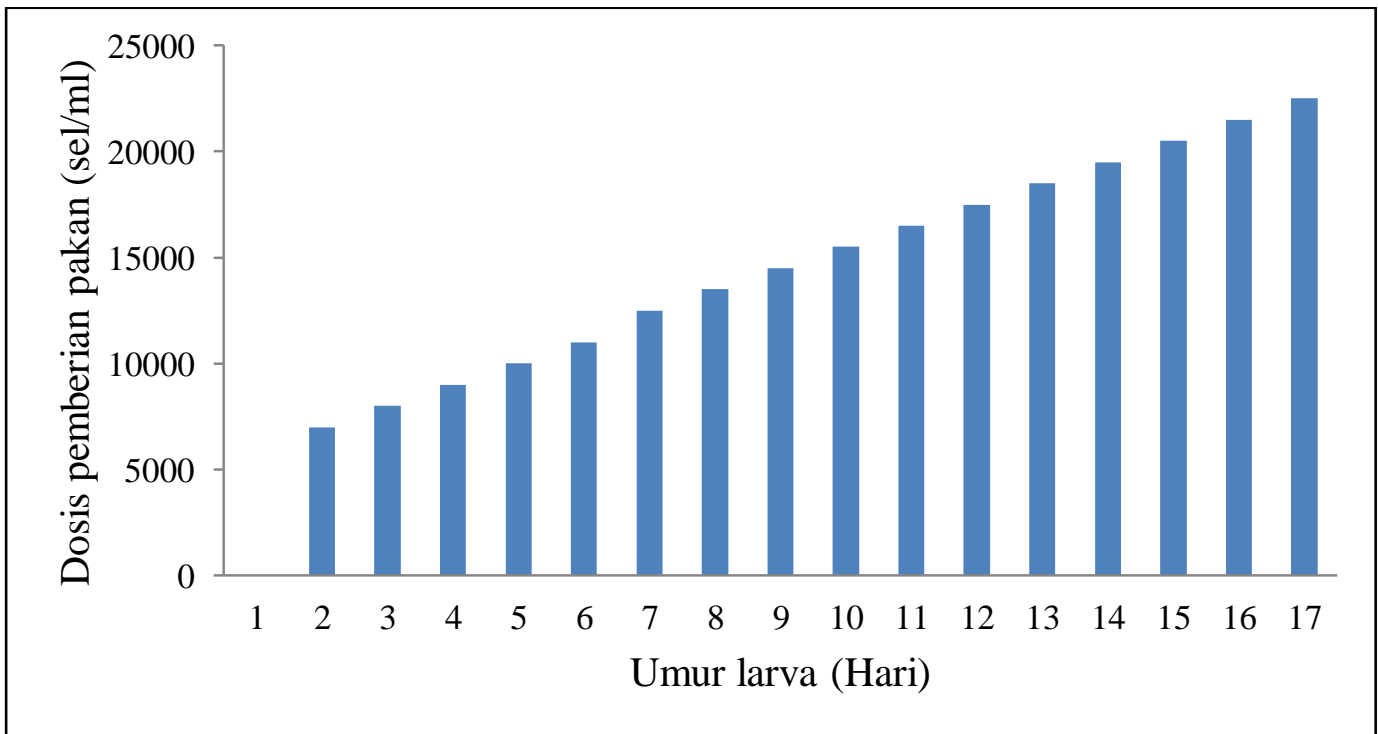

Gambar 1. Dosis Pemberian Pakan Alami Larva Kerang Mutiara Selama Masa Penelitian

\section{Kualitas Air Media Pemeliharaan}

Pengukuran kualitas air yang diukur pada media budidaya anatara lain suhu air, salinitas, dan pH. Pengukuran dari setiap parameter dilakukan pada masing-masing perlakuan, dengan periode pengukuran dua hari sekali pada pukul 08.00 WITA. Data hasil pengukuran kualitas air disajikan pada tabel 1.

Tabel 1. Data Pengukuran Kualitas Air Pada Media Pemeliharaan

\begin{tabular}{|c|c|c|c|c|c|c|c|c|c|c|c|c|c|c|c|c|c|c|}
\hline \multirow[t]{2}{*}{ Hari } & \multicolumn{6}{|c|}{ Suhu air $\left({ }^{0} \mathrm{C}\right)$} & \multicolumn{6}{|c|}{ Salinitas (ppt) } & \multicolumn{6}{|c|}{$\mathrm{pH}$} \\
\hline & $\mathrm{A}$ & $\mathrm{B}$ & $\mathrm{C}$ & $\mathrm{D}$ & $E$ & $*$ & $\mathrm{~A}$ & B & $\mathrm{C}$ & $\mathrm{D}$ & $\mathrm{E}$ & $* *$ & $\bar{A}$ & B & $\mathrm{C}$ & $\mathrm{D}$ & $\mathrm{E}$ & *** \\
\hline 3 & 29 & 29 & 29 & 29 & 29 & & 32 & 32 & 32 & 32 & 32 & & 8 & 8 & 8 & 8 & 8 & \\
\hline 5 & 29 & 28 & 29 & 28 & 29 & & 32 & 32 & 32 & 32 & 32 & & 8 & 8 & 8 & 8 & 8 & \\
\hline 7 & 29 & 29 & 29 & 29 & 29 & & 32 & 32 & 32 & 32 & 32 & & 8 & 8 & 8 & 8 & 8 & \\
\hline 9 & 29 & 29 & 29 & 28 & 29 & & 32 & 32 & 32 & 32 & 32 & & 8 & 8 & 8 & 8 & 8 & \\
\hline 11 & 29 & 29 & 29 & 29 & 29 & & 32 & 32 & 32 & 32 & 32 & & 8 & 8 & 8 & 8 & 8 & \\
\hline 13 & 29 & 29 & 28 & 29 & 29 & & 32 & 32 & 32 & 32 & 32 & & 8 & 8 & 8 & 8 & 8 & \\
\hline 15 & 29 & 29 & 29 & 29 & 28 & & 32 & 32 & 32 & 32 & 32 & & 8 & 8 & 8 & 8 & 8 & \\
\hline 17 & 28 & 29 & 29 & 29 & 29 & & 32 & 32 & 32 & 32 & 32 & & 8 & 8 & 8 & 8 & 8 & \\
\hline
\end{tabular}

Keterangan:

$\mathrm{A}=$ intensitas cahaya 0 lux

$\mathrm{B}=$ intensitas cahaya 50 lux

$\mathrm{C}=$ intensitas cahaya 100 lux

$\mathrm{D}=$ intensitas cahaya 150 lux

$\mathrm{E}=$ intensitas cahaya 200 lux

* = suhu air optimum untuk perkembangan $P$. maxima $28-30^{\circ} \mathrm{C}$ (Sutaman, 1993)

** = salinitas optimum untuk perkembangan $P$. maxima 30-32 ppt (Gosling, 2004)

*** $=$ pH optimum untuk perkembangan $P$. maxima 7,9-8,2 (Winanto, 2004)

Pada media pemeliharaan larva diperoleh suhu air berkisar $28-29{ }^{\circ} \mathrm{C}$, salinitas $32 \mathrm{ppt}$, dan pH air 8. Dari hasil pengukuran parameter air media didapatkan bahwa masing-masing nilai dari parameter yang diukur hampir sama pada setiap perlakuan dan masih dalam kisaran optimum bagi perkembangan larva kerang mutiara, dari hasil ini dapat diasumsikan bahwa faktor tunggal yang mempengaruhi pertumbuhan dan laju sintasan adalah intensitas cahaya yang berbeda.

Menurut Goddard (1996), pada kondisi suhu dan salinitas optimum terjadi laju metabolisme maksimum, sehingga bisa dicapai pertumbuhan dan laju sintasan maksimum. Suhu dan salinitas berpengaruh terhadap kecepatan dan keberhasilan pertumbuhan awal larva Pinctada imbricata (Gosling, 2004). 


\section{Pertumbuhan Larva Kerang Mutiara (Pinctada maxima)}

Berdasarkan hasil penelitian, pengamatan pertumbuhan larva kerang mutiara ( $P$. maxima) pada stadia D-larva (hari ke-2), umbo awal (hari ke-6), umbo akhir (hari ke-7), eye spot (hari ke-14), pediveliger (hari ke-15), plantigrade (hari ke-18).

Pertumbuhan larva pada intensitas cahaya 0 lux merupakan pertumbuhan larva yang paling rendah dibanding dengan intensitas cahaya yang lain. Pertumbuhan tercepat pada hari ke (15-18) yaitu sebesar 105,89 $\mu \mathrm{m}$.

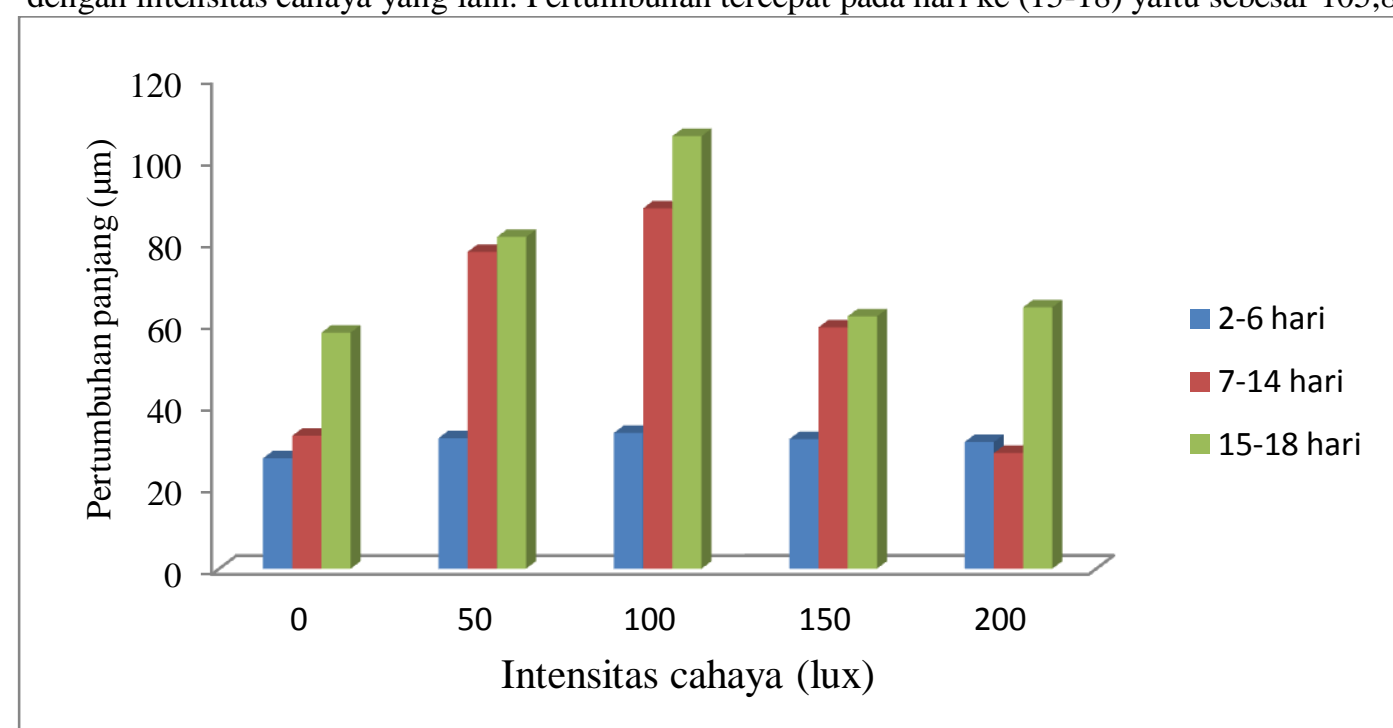

Gambar 2. Pertumbuhan Panjang Larva Kerang Mutiara (P. maxima)

Petumbuhan larva kerang mutiara yang dipelihara dengan intensitas cahaya yang berbeda, mengalami penambahan panjang cangkang yang berbeda setiap hari selama masa pemeliharaan. Penambahan panjang cangkang diukur dari fase D-larva sampai dengan fase plantigrade. Berdasarkan hasil pengujian statistik One Way Anova menunjukkan tidak terdapat perbedaan nyata intensitas cahaya $0,50,100,150$, dan 200 lux terhadap pertumbuhan larva kerang mutiara.

Namun bila dilihat data pertumbuhan larva hasil penelitian, pada setiap perlakuan perbedaan intensitas cahaya, ternyata pada intensitas cahaya 50 dan 100 lux cenderung lebih baik jika dibandingkan dengan perlakuan intensitas cahaya lainnya, walupun perbedaanya tidak terlalu mencolok.

Berdasarkan hasil penelitian diketahui bahwa larva P. maxima menghendaki kondisi lingkungan pemeliharaan dengan intensitas cahaya yang sedang, artinya tidak terlalu tinggi dan bukan tidak terdapat cahaya sama sekali yaitu pada intensitas cahaya 50-100 lux. Hal ini dapat disimpulkan bahwa larva kerang mutiara bersifat fototaksis positif. Hasil ini juga dipertegas oleh pernyataan Alagarswami et al. (1987), larva tiram mutiara $P$. fucata mempunyai preferensi kondisi lingkungan dengan pencahayaan rendah dan untuk memanipulasi lingkungan digunakan wadah pemeliharaan yang berwarna gelap dan hasilnya larva menunjukkan perkembangan yang baik serta waktu penempelan yang cepat.

Dalam penelitian ini diperoleh informasi bahwa pertumbuhan larva kerang mutiara tertinggi pada intensitas cahaya 50 dan 100 lux. Hal ini diduga berkaitan dengan laju metabolisme larva. Pada kondisi dengan cahaya yang sesuai dengan kebutuhan yang tepat maka dapat meningkatkan ritme metabolisme larva, sehingga larva dapat tumbuh dengan baik. Zuang (2006) menyampaikan, laju mencerna makanan berkaitan dengan laju metabolisme dan efektifitas metabolisme, nantinya akan mempengaruhi energi yang dihasilkan untuk pertumbuhan dan aktivitas biologis lainnya.

\section{Laju Sintasan Larva Kerang Mutiara (Pinctada maxima)}

Hasil percobaan menunjukkan bahwa intensitas cahaya memiliki pengaruh terhadap laju sintasan. Sintasan tertinggi pada stadia D-larva-umbo awal yaitu pada hari 2-6 sebesar 86,6 \% dengan intensitas cahaya 50 lux. Kemudian masih pada stadia D-larva-umbo awal 100 lux yaitu sebesar 82,6\%, 150 lux 81,2 \%, dan terendah pada 0 lux yaitu sebesar $79,2 \%$. Hasil yang sama juga terjadi pada stadia umbo akhir-eye spot dan pediveliger-plantigrade. Data laju sintasan larva kerang mutiara (P. maxima) disajikan pada gambar 3 


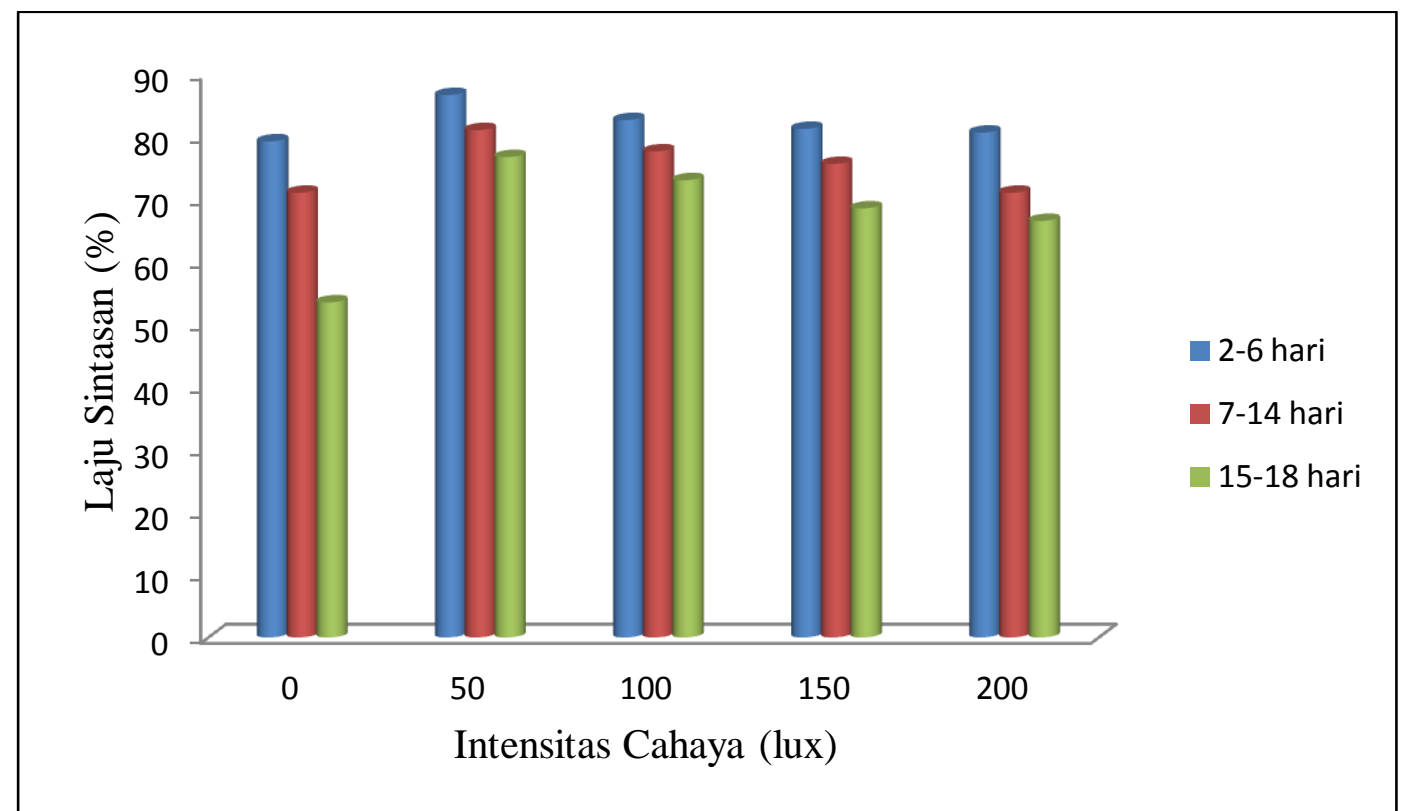

Gambar 7. Persentase Laju Sintasan Larva Kerang Mutiara (P. maxima) Pada Berbagai Tingkat Intensitas Cahaya

Berdasarkan perhitungan dan pengolahan data statistik mengenai laju sintasan atau kelulushidupan larva kerang mutiara P. maxima pada masing-masing perlakuan intensitas cahaya, dapat diketahui bahwa tidak ada pengaruh nyata intensitas cahaya yang berbeda terhadap laju sintasan kerang mutiara. Namun bila dilihat data pengukuran laju sintasan larva, hampir sama dengan hasil pengukuran pertumbuhan. Pada intensitas cahaya 50 dan 100 lux cenderung lebih tinggi jika dibandingkan dengan perlakuan intensitas cahaya lainnya, walupun perbedaanya tidak terlalu mencolok.

Dilihat secara keseluruhan, selama masa pemeliharaan dari stadia D-larva sampai dengan stadia plantigrade terjadi penurunan sintasan pada setiap tahap stadia. Laju sintasan paling tinggi terdapat pada intensitas cahaya 50 lux sebesar 76,7-86,6 \%, sedangkan laju sintasan yang terendah pada intensitas cahaya 0 lux sebesar 53,5-79,2\%.

\section{Kesimpulan}

Berdasarkan hasil analisis statistik penelitian, tidak terdapat perbedaan nyata, maka dapat diambil kesimpulan sebagai berikut:

1. Berdasarkan pengamatan secara deskriptif, intensitas cahaya berbeda mempengaruhi pertumbuhan larva kerang mutiara (P. maxima). Intensitas cahaya 50 dan 100 lux cenderung mempengaruhi pertumbuhan larva kerang mutiara.

2. Berdasarkan pengamatan secara deskriptif, intensitas cahaya berbeda mempengaruhi laju sintasan larva kerang mutiara (P. maxima). Intensitas cahaya 50 dan 100 lux cenderung mempengaruhi laju sintasan larva kerang mutiara.

\section{Daftar Pustaka}

Alagarswami, K., Dharmaraj, S., Velayudhan, T. S and Chellam, A., 1987. Hatchery Tecnology for Pearl Oyster Production. Pearl Culture CMFRI cochin, India Bull. 39(9): 62-71.

Gosling, E., 2003. Bivalve Molluscs. Biology, Ecology, and Culture. Fishing New Book. Great Britain.

Rupp G. S., Parsons, G. J., Thompson, R. J., \& de Bem, M. M., 2005. Influence of Environmental Factors, Season and Size at Development on Growth and Retieval of Postlarval Lion's Paw Scallop Nodipecten nodusus (Linnaeus, 1758) From A Subtropical Environment. Aquaculture 243: 195-216.

Sujoko, A. 2010. Membenihkan Kerang Mutiara. Insan Madani. Yogyakarta.

Sutaman. 1993. Tiram Mutiara Teknik Budidaya dan Proses Pembuatan Mutiara. Penerbit Kanisius. Yogyakarta. 128 hlm.

Winanto, T. 2004. Memproduksi Benih Tiram Mutiara. Penebar Swadaya, Jakarta. 95 hlm. 